Synthesis of Natural

Products and

Potential Drugs

\section{Synthesis of Vaniprevir}<smiles>C=CCc1cccc2c1CN(C(=O)OC1CC(C(=O)O)N(C(=O)[C@H](NC(=O)OCC(C)(C)CC)C(C)(C)C)C1)C2</smiles>

$<92 \%$ HPLC purity<smiles>CC(C)(F)COC(=O)N[C@H](C(=O)N1C[C@@H](OC(=O)N2Cc3cccc(C/C=C/CC(C)(C)CO)c3C2)CC1C(=O)O)C(C)(C)C</smiles>

E

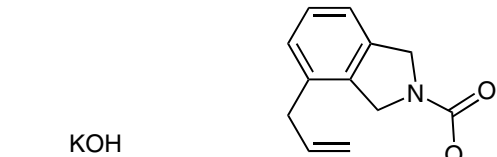

$\stackrel{i-\mathrm{PrOH}}{\longrightarrow}$

r.t., $16 \mathrm{~h}$

$92 \%$<smiles>[R]OC(=O)C1C[C@@H](O)CN1C(=O)[C@@H](NC(=O)OCC(C)(C)CC=C)C(C)(C)C</smiles>

white solid; mp not reported $>97 \%$ HPLC purity

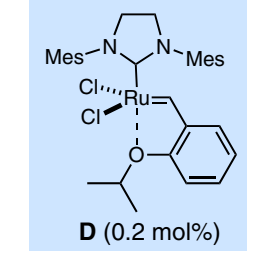

2,6-DCQ (0.1 equiv) PhMe $(13.5 \mathrm{~mL} / \mathrm{g})$ $100{ }^{\circ} \mathrm{C}, 1.5 \mathrm{~h}$ $91 \%$ (30.7 mmol scale) 2,6-DCQ = 2,6-dichloro-1,4-benzoquinone

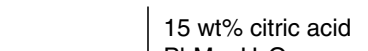

Key words

vaniprevir

MK-7009

HCV protease inhibitors

ring-closing metathesis

macrocyclization

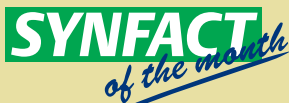

\begin{tabular}{r|}
$\mathrm{H}_{2}(45 \mathrm{psi}), 5 \% \mathrm{Pd} / \mathrm{C}$ \\
i-PrOH-PhMe, r.t., $24 \mathrm{~h}$ \\
then $\mathrm{KOH}, \mathrm{EtOH}$
\end{tabular}<smiles>CC(C)(F)COC(=O)NC(C(=O)N1CC(OC(=O)N2Cc3cccc(CCCCC(C)(C)C(=O)O)c3C2)CC1C(=O)O)C(C)(C)F</smiles>

white solid; $\mathrm{mp}$ not reported

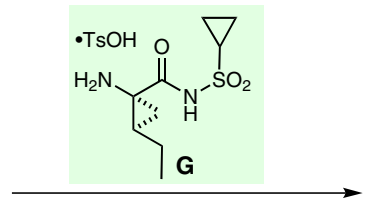

EDC, py, MeCN-i-PrOAc crystallize from $i$-PrOAc-heptane $84 \%$

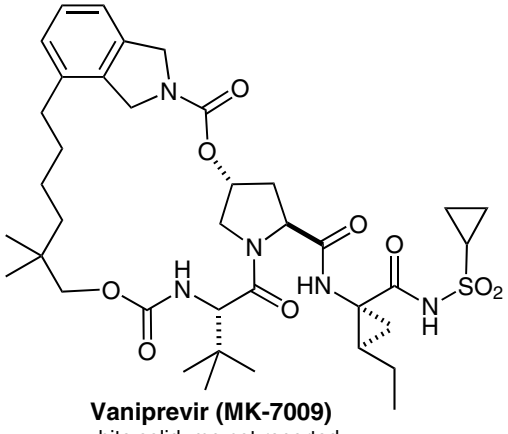

white solid; $\mathrm{mp}$ not reported
Significance: The key step in this synthesis of vaniprevir is the construction of the macrocycle (91\% yield) via ring-closing metathesis (RCM). By using simultaneous slow addition of the substrate and the catalyst $\mathbf{D}(0.2 \mathrm{~mol} \%)$, the $\mathrm{RCM}$ reaction could be conducted at high concentration (0.13 M) on a $100 \mathrm{~g}$ scale.
Comment: 2,6-Dichloro-1,4-benzoquinone was added to suppress isomerization of the allyl alkene in the isoindoline unit in $\mathbf{C}$ and consequent competing formation of a 19-membered ring by-product. An important contributor to the success of the RCM reaction was the high purity of crystalline B.

SYNFACTS Contributors: Philip Kocienski

Synfacts 2012, 8(7), 0693 Published online: 19.06.2012

Dol: 10.1055/s-0031-1290413; Reg-No.: K03112SF 